\title{
Clinic-Based Patellar Mobilization Therapy for Knee Osteoarthritis: A Randomized Clinical Trial
}

\author{
Regina Wing Sban Sit ${ }^{1}$ \\ Keitb Kwok Wai Chan ${ }^{1}$ \\ Dan Zou, MPH \\ Dicken Cheong Cbun Chan, MSc' \\ Benjamin Hon Kei Yip, $P b D^{1}$ \\ Daisy Dexing Zhang, $\mathrm{PbD}^{1}$ \\ Ying Ho Chan ${ }^{1}$ \\ Vincent Cbi Ho Cbung, PbD ${ }^{1}$ \\ Kenneth Dean Reeves, $M D^{2}$ \\ Samuel Yeung Shan Wong, $M D^{1}$ \\ ${ }^{1}$ The School of Public Health and Primary \\ Care, The Chinese University of Hong \\ Kong, Hong Kong \\ ${ }^{2}$ Private Practice, Roeland Park, Kansas
}

\begin{abstract}
PURPOSE We performed a phase 2 randomized clinical trial to evaluate the preliminary effectiveness of a clinic-based patellar mobilization therapy (PMT) in patients with knee osteoarthritis.

METHODS We recruited 208 patients with knee osteoarthritis at primary care clinics in Hong Kong. Patients were randomly assigned $(1: 1)$ to the intervention group or the control group. The intervention group received 3 PMT treatment sessions from primary care physicians at 2-month intervals, with concomitant prescription of a home-based vastus medialis oblique muscle exercise. The control group received PMT after the study period. The primary outcome was the Western Ontario and McMaster Universities Osteoarthritis Index (WOMAC) pain score. Secondary outcomes included the WOMAC composite, function, and stiffness scores; the visual analog scale score for pain; objective physical function tests (30-s chair stand, 40-m walk test, timed up and go test, and EuroQol-5D). All outcomes were evaluated at baseline and at 24 weeks through intention-to-treat analysis.
\end{abstract}

RESULTS We observed no baseline between-group differences. The WOMAC pain score showed greater improvement in the intervention group than in the control group at 24 weeks (between-group difference $-15.6,95 \% \mathrm{Cl},-20.5$ to $-10.7, P<.001)$. All secondary outcomes also demonstrated significant betweengroup differences.

CONCLUSIONS Patellar mobilization therapy has the potential to reduce pain and improve function and quality of life for patients with knee osteoarthritis. Future clinical trials with comparison to other active comparator controls will help determine the overall efficacy and facilitate the deployment of PMT in realworld practice.

Ann Fam Med 2018;16:521-529. https://doi.org/10.1370/afm.2320.

\section{INTRODUCTION}

$\mathrm{K}$ nee osteoarthritis is a major cause of pain and disability that contributes to the health care service burden worldwide. ${ }^{1}$ Knee osteoarthritis is commonly diagnosed and managed by primary care physicians $\mathrm{s}^{2,3}$; unfortunately, therapeutic options are often limited. Exercise and weight reduction strategies can effectively manage knee osteoarthritis; however, fatigue, comorbidities, and the arthritic process itself hinder patient participation in such interventions. ${ }^{4}$ Although physiotherapy is known to reduce knee pain and improve the quality of life of patients, ${ }^{5}$ it may not be available due to limited access and high cost. Analgesics are commonly prescribed by primary care physicians, although they either provide minimal short-term pain relief or are associated with significant adverse effects, especially in elderly populations. ${ }^{6-8}$ Therefore, the search for effective treatment modalities for knee osteoarthritis remains a top priority in clinical practice and research.

The knee joint, a complex tri-compartment structure, comprises the patellofemoral joint and the tibiofemoral joint. The coexistence of patellofemoral joint osteoarthritis and tibiofemoral joint osteoarthritis is 
observed in $40 \%$ of older adults with knee osteoarthritis. ${ }^{9}$ Previous studies have indicated that patellofemoral joint osteoarthritis is a major source of pain in knee osteoarthritis, and that the concomitant occurrence of patellofemoral joint osteoarthritis and tibiofemoral joint osteoarthritis causes a greater degree of pain and loss of function. ${ }^{9-11}$

Presently, clinical guidelines recommend using nonpharmacological strategies as the first-line treatment for knee osteoarthritis and propose individualizing treatment based on the site of joint damage. ${ }^{12-14}$ One approach is to use combined interventions of manual therapy and exercise. ${ }^{15,16}$ Only a few clinical trials, however, have evaluated the role of manual therapy that targets patellofemoral joint osteoarthritis, ${ }_{1}^{17,18}$ and they are limited by small sample size, lack of methodological rigor, ${ }^{17}$ or heterogeneous interventions. ${ }^{18}$

We evaluated whether a simple clinic-based patella mobilization therapy (PMT) used in primary care settings could effectively reduce pain and improve function and quality of life in patients with concomitant patellofemoral joint osteoarthritis and tibiofemoral joint osteoarthritis.

\section{METHODS}

The Joint Chinese University of Hong Kong-New Territories East Cluster Clinical Research Ethics Committee (CREC no 2014.379) approved this study. All patients provided written informed consent. We prospectively registered the trial at the Chinese Clinical Trial Registry (\#ChiCTR-IPC-15006618). The details of our study methodology have been reported in the protocol. ${ }^{19}$

\section{Patients and Study Setting}

The study was a 24-week, 2-arm, parallel, superiority, phase 2 randomized controlled trial. We studied patients from 7 general outpatient clinics in the New Territories East region of Hong Kong at a university primary care clinic. All patients were of Chinese ethnicity and spoke Cantonese as their first language.

The inclusion criteria were adults aged 45 to 75 years; a diagnosis of knee osteoarthritis based on clinical and radiographic criteria defined by the American Rheumatology Association ${ }^{20}$; knee pain score of $\geq 3$ (0-6 ordinal response score) for at least 3 months during activities such as stair climbing, squatting, or prolonged sitting ${ }^{21}$; anterior knee pain and any 2 of the following criteria on initial assessment: (1) pain on direct compression of the patella against the femoral condyles with the knee in full extension, (2) tenderness on palpation of the posterior patellar surface, (3) pain on resisted knee extension, and (4) pain with isometric quadriceps contraction against suprapatellar resistance with the knee in slight flexion ${ }^{15,21}$; and the presence of osteophytes in the patellofemoral joint on $30^{\circ} \mathrm{flex}$ ion lateral radiographs. ${ }^{22}$ The exclusion criteria were a history of open or arthroscopic operation on the symptomatic knee; a body mass index of $\geq 35 \mathrm{~kg} / \mathrm{m}^{2}$; any knee injections within the preceding month; a history of inflammatory or post-infectious knee arthritis; daily opioid medication, fixed flexion deformity $>5^{\circ}$ or varus/valgus deformity $>15^{\circ}$ i and severe comorbidities preventing study participation.

\section{Randomization, Allocation, Concealment, and Blinding}

An off-site statistician performed block randomization to allocate patients into 2 groups in a 1:1 ratio using the Random Allocation Software version 1.0 (M Saghaei, Isfahan University of Medical Sciences). ${ }^{23}$ The allocation sequence was concealed from the researcher and patients by using sequentially numbered, opaque, sealed envelopes. ${ }^{24}$ The envelopes were opened after the enrolled patients had completed all baseline assessment at the time of groups were allocated. In this open-label study, blinding of physicians and patients was not possible. However, research assistants and statisticians, who were involved with data collection and statistical analysis, respectively, were blinded to the allocation status.

\section{Intervention Group}

The PMT protocol comprised patellofemoral joint mobilization ( 5 minutes) followed by supervised nonload vastus medialis oblique exercise (5 minutes). Trained primary care physicians performed all interventions. Patients with bilateral knee pain received treatment in both knees. The intervention was performed in 2 steps. In step 1, the patellofemoral joint was mobilized once every 2 months for a total of 3 treatment sessions. Mobilization was based on the observation that in patients with patellofemoral joint osteoarthritis, the patella shows lateral displacement because of the imbalance vectors. ${ }^{25,26}$ Patients were placed in a side-lying position with the knee supported using a wedge and slightly flexed to a degree that allowed a vertical gravitational glide of the patella in a lateral to medial direction. ${ }^{27}$ In step 2, the same physicians prescribed active nonload vastus medialis oblique exercise, to encourage continuous firing of the muscle, based on the fact that decreased motor recruitment is common in patients with knee osteoarthritis. ${ }^{28}$ The physicians supervised the patients to ensure that they performed the exercises correctly, and a home-exercise program was encouraged twice daily with 20 repetitions/session. We provided each patient with an exercise pamphlet as a reference. 


\section{Control Group}

The control group was placed on a waiting list, was contacted by telephone at the same time interval as the PMT sessions, and completed all outcome measures within the same time frame. All patients received the same PMT after study completion at 24 weeks.

Both the intervention group and the control group received the same standard care. Cointerventions using conventional medication, physical therapy, acupuncture, herbal and over-the-counter drugs, and other active treatments were allowed. We did not restrict either physicians or patients from providing or seeking other interventions during the study period.

\section{Outcome Measures}

Data for all outcome measures were collected at baseline and again at 24 weeks, which was the primary endpoint of the study. The primary outcome was the Western Ontario and McMaster Universities Osteoarthritis Index (WOMAC) pain score, which is the reference standard for self-reported measures in knee osteoarthritis trials. ${ }^{29}$ The WOMAC comprises 24 self-reported items for knee pain (5 items), stiffness (2 items), and function (17 items), each measured with 0-100 mm scale. ${ }^{30}$ Secondary outcomes included the WOMAC function, stiffness, and composite scores; the 3 objective physical function measures recommended for knee osteoarthritis trials, ${ }^{31}$ (30-s chair stand performance, 40-m fast-paced walk, and timed up and go test); and the EuroQuol-5D score as a measure of health-related quality of life. ${ }^{32}$ We used the visual analog scale $(0-100 \mathrm{~mm})$ to rate knee pain while walking in the past 48 hours. We used a goniometer to measure the degree of pain-free active knee flexion, ${ }^{33}$ and a 7-day recall diary to record the number of patients taking analgesics the week before testing and to check their exercise compliance.

We recorded patient demographics, body mass index, duration of knee pain, prior knee interventions, and number of comorbidities. We assessed the patients' baseline physical activity status by using the International Physical Activity Questionnaire. ${ }^{34}$ We used the Kellgren-Lawrence classification system to grade the severity of knee osteoarthritis, ${ }^{35}$ and confirmed the presence of patellofemoral joint osteoarthritis on lateral radiographs. We examined the patellar position ultrasonographically by measuring the horizontal distance between the center of the patellar tendon and the femoral groove, with the knee fully extended. We used the Stanford Expectations of Treatment Scale to overcome the influence of patient expectations on treatment response. ${ }^{36} \mathrm{We}$ also recorded any serious adverse events.

\section{Sample Size Calculation}

We calculated the sample size based on a trial performed by Abbott et al, with a Cohen's $d$ value of 0.42 favoring combined manual therapy and exercise vs standard care used for the management of knee osteoarthritis. ${ }^{37}$ We used the same Cohen's $d$, with a 2 -sided $t$-test, a type I error at 0.05 of $80 \%$ power, and a sample size of 90 in each group. Assuming a dropout rate of $15 \%$, the adjusted total sample size was 208 .

\section{Data and Statistical Analysis}

We presented categorical variables as counts and percentages, and continuous variables as mean and standard deviation (SD) or median (interquartile range). We compared intergroup baseline characteristics by using the $\chi^{2}$ test for categorical variables and the 2 -sample independent $t$-test for continuous variables. We performed analysis of covariance to compare the effects between the intervention group and the control group for all outcomes, following the intentionto-treat principle. Baseline scores, duration of knee pain, number of comorbidities, status of bilateral knee pain, total amount of analgesics consumed during the study period, and age were studied as covariates and controlled in the analysis. Additionally, we performed a per-protocol analysis after including patients who completed their treatment as originally assigned. We performed sensitivity analysis to assess the effect of missing data, by using multiple imputation models. We imputed 20 completed datasets by using chain equations under the assumption that data were missing at random until the chain reaches convergence. ${ }^{38} \mathrm{We}$ applied Rubin's rule to combine the effect estimates. ${ }^{39}$ This approach provides estimated standard errors and $P$ values that incorporate missing data uncertainty. A few patients had bilateral knee treatment; therefore, in those patients, we considered both knees to compare scores on the visual analog scale and degree of pain-free active knee flexion by using linear mixed models. A 2-sided $P$ value of $\leq .05$ was considered statistically significant. A stopping rule was applied to patients who received alternative surgical treatment or developed severe outcomes during the study period. We used Stata version 14.0 (StataCorp LLC) software for all statistical analyses. ${ }^{40}$

\section{RESULTS}

The recruitment period was between June 2015 and November 2017. Of the 401 patients screened, we enrolled 208 patients and randomized them into 2 groups with 104 patients each (Figure 1). All patients completed the baseline questionnaire and were included in the intention-to-treat analysis. The dropout rate was $6 \%(6 / 104)$ in the intervention group and 


\section{Figure 1. Flow chart of the trial.}

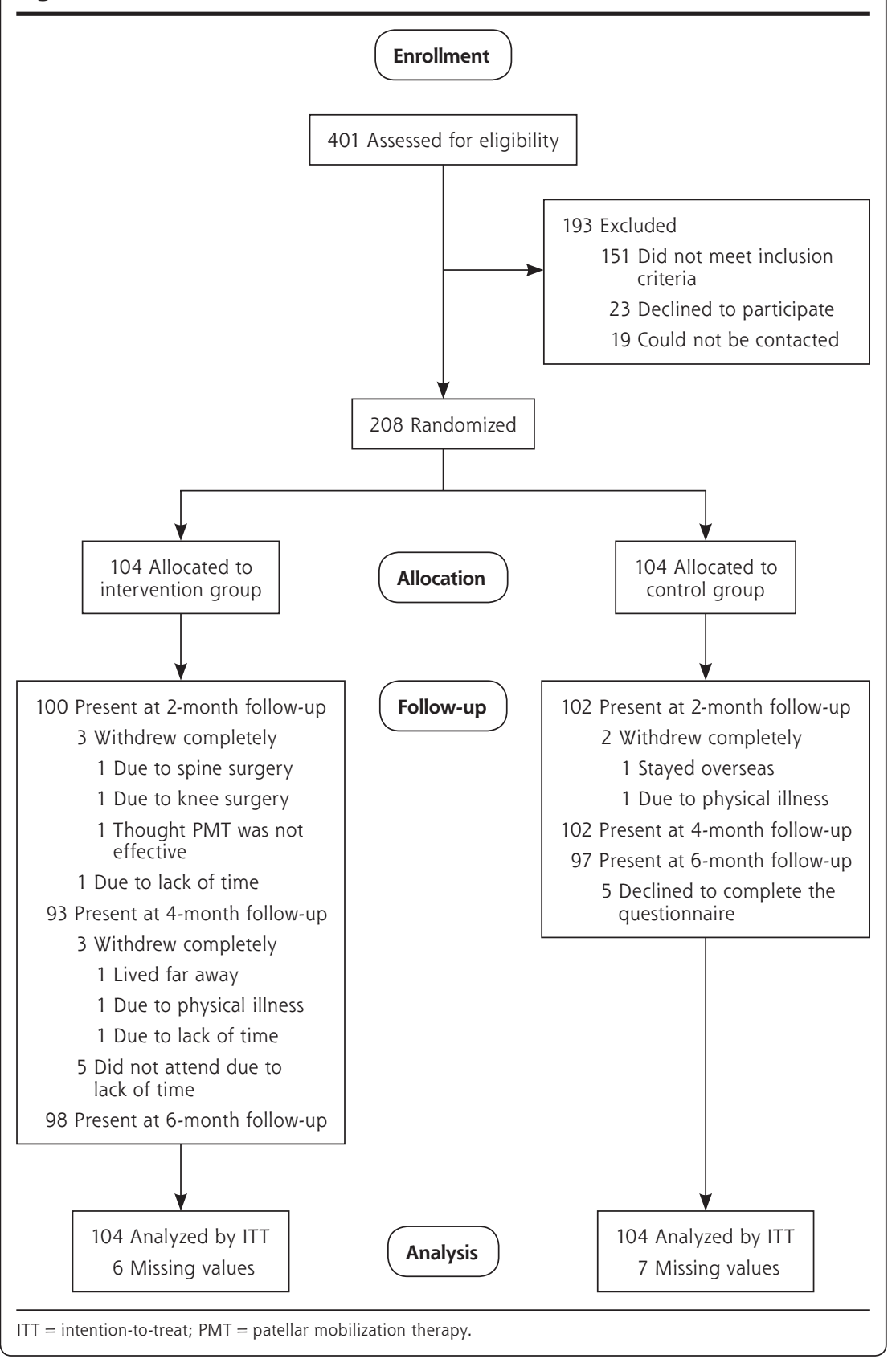

ment expectations, and $83.2 \%$ of the patients remained minimally active. Among patients who completed the study, the total number of knees involved was 160 in the intervention group and 166 in the control group. The center of the patella was $0.90(\mathrm{SD} \mathrm{0.24)} \mathrm{cm}$ lateral to the femoral groove (Tables 1 and 2).

Between-group comparison showed that patients in the intervention group demonstrated significantly greater improvement in their WOMAC pain score than those in the control group at 24 weeks (between-group difference $-15.6,95 \% \mathrm{CI},-20.5$ to -10.7 , $P<.001)$. The WOMAC composite, pain, and function scores; visual analog scale pain score ${ }_{i} 30$-s chair stand performance; 40 -m fast-paced walk test $t_{i}$ timed up and go test ${ }_{i}$ and EuroQoL-5D score also showed significant between-group differences. There were no significant between-group differences between the intervention and control groups in terms of the number of patients who were taking analgesics $(10.1 \%$ vs $9.3 \%, P=0.846)$ and the range of knee flexion at 24 weeks (Tables 3, 4, and 5).

We observed high patient compliance in terms of nonload vastus medialis oblique exercise. Patients from the intervention group practiced the exercise for a mean of 5.2 (SD 2.1) days

$6.7 \%(7 / 104)$ in the control group. Patients in the intervention group underwent a mean of 2.9 (SD 0.4) PMT treatment sessions.

We observed no statistically significant difference in demographic and outcomes at baseline. The study sample comprised $80.3 \%$ women with a mean age of 60.2 (SD 5.7) years. In the total population, $23.1 \%$ overweight and $38 \%$ were obese. The mean duration of knee pain was 7.7 (SD 6.6) years, and $62 \%$ of the patients had knee osteoarthritis of Kellgren-Lawrence grade 2 or $3 .{ }^{35}$ Both groups demonstrated similar treat- per week. Notably, 1 patient in the intervention group developed increased knee pain after the PMT and discontinued the intervention after the second session. No other adverse events were reported.

\section{DISCUSSION}

In this phase 2 study, we observed that simple clinicbased PMT could potentially reduce knee pain and stiffness, improve knee function, and positively affect the quality of life in patients with concomitant patel- 
lofemoral joint osteoarthritis and tibiofemoral joint osteoarthritis. The change appeared to be clinically meaningful; the improvement of the overall WOMAC composite score in the intervention group exceeded the minimal clinically important difference of 12 points in rehabilitation intervention for knee osteoarthritis. ${ }^{41}$ patella in patellofemoral joint osteoarthritis. ${ }^{10,45}$ Studies targeting treatment of patellofemoral joint osteoarthritis through medial taping and patellar brace all aimed to reduce pain by increasing the patellofemoral contact area, thereby decreasing joint stress and bone marrow lesions adjacent to the patellofemoral joint compart-
Our present findings also suggest that the knee-specific effects of PMT may have a more general impact on quality of life, given that the EuroQoL-5D scores improved in excess of the minimal clinically important difference of 0.03 points for chronic conditions. ${ }^{42}$ This is supported by the observation that patients in the intervention group performed consistently better than the control group in all outcomes.

We used a combined intervention of passive joint mobilization to realign the patella, and active vastus medialis oblique firing to maintain the patellar position. We did not separately evaluate the effect of each component, as we believed they were complementary to each other. With reference to a Cochrane review of exercise for knee osteoarthritis, ${ }^{43}$ the pooled results from 44 trials indicated that exercise alone can significantly reduce pain by 12 points and improve physical function by 10 points on a 100 point scale. In our study, the application of patellar mobilization in combination with exercise, demonstrated a larger improvement of pain and function scores by 17 and 18 points, respectively, which further supports the recommendation of combined interventions for knee osteoarthritis. ${ }^{15,16}$

To date, the reference standard for accurate radiological measurement of patellar alignment has not been established. ${ }^{44}$ However, the distance between the center of the patella and the femoral groove measured in our study was consistent with previous literature regarding the tendency for lateral tracking of the
Table 1. Baseline Characteristics of Participants

\begin{tabular}{|c|c|c|c|}
\hline Characteristic & $\begin{array}{c}\text { Total } \\
(n=208)\end{array}$ & $\begin{array}{c}\text { Intervention } \\
\text { Group } \\
(n=104)\end{array}$ & $\begin{array}{l}\text { Control } \\
\text { Group } \\
(n=104)\end{array}$ \\
\hline Age, mean (SD), y & $60.2(5.7)$ & $59.4(5.6)$ & $60.9(5.8)$ \\
\hline \multicolumn{4}{|l|}{ BMI, No. (\%) } \\
\hline$<18.5$ (underweight) & $5(2.4)$ & $1(1.0)$ & $4(3.8)$ \\
\hline 18.5 to $<23.0$ (normal) & $76(36.5)$ & $37(35.6)$ & $39(37.5)$ \\
\hline 23.0 to $<25.0$ (overweight) & $48(23.1)$ & $23(22.1)$ & $25(24.0)$ \\
\hline$\geq 25.0$ (obese) & $79(38.0)$ & $43(41.3)$ & $36(34.6)$ \\
\hline \multicolumn{4}{|l|}{ Sex, No. (\%) } \\
\hline Male & $41(19.7)$ & $19(18.3)$ & $22(21.2)$ \\
\hline Female & $167(80.3)$ & $85(81.7)$ & $82(78.8)$ \\
\hline \multicolumn{4}{|l|}{ Number of chronic diseases, No. (\%) } \\
\hline 1 & $68(32.7)$ & $35(33.7)$ & $33(31.7)$ \\
\hline 2 & $64(30.8)$ & $32(30.8)$ & $32(30.8)$ \\
\hline$\geq 3$ & $76(36.5)$ & $37(35.6)$ & $39(37.5)$ \\
\hline Duration of knee pain, mean (SD), y & $7.7(6.6)$ & $6.9(5.5)$ & $8.5(7.4)$ \\
\hline \multicolumn{4}{|l|}{$\begin{array}{l}\text { Stanford Expectations of Treatment } \\
\text { Scale, mean (SD) }\end{array}$} \\
\hline Positive expectancy & $2.42(0.90)$ & $2.44(0.89)$ & $2.39(0.91)$ \\
\hline Negative expectancy & $5.33(1.18)$ & $5.41(1.20)$ & $5.25(1.16)$ \\
\hline IPAQ median (IQR), MET score & $\begin{array}{l}3,284.8 \\
(2,566.0)\end{array}$ & $\begin{array}{l}3,353.6 \\
(2,712.5)\end{array}$ & $\begin{array}{l}3,216.0 \\
(2,445.8)\end{array}$ \\
\hline Inactive, No. (\%) & $14(6.7)$ & $9(8.7)$ & $5(4.8)$ \\
\hline Minimally active, No. (\%) & $173(83.2)$ & $84(80.8)$ & $89(85.6)$ \\
\hline HEPA active, No. (\%) & $21(10.1)$ & $11(10.6)$ & $10(9.6)$ \\
\hline Prior treatment for OA knee, No. (\%) & $128(61.5)$ & $61(58.7)$ & $67(64.4)$ \\
\hline Knee exercise & $25(12.0)$ & $10(9.6)$ & $15(14.4)$ \\
\hline Physiotherapy & $91(43.8)$ & $45(43.3)$ & $46(44.2)$ \\
\hline Traditional Chinese medicine & $79(38.0)$ & $38(36.5)$ & $41(39.4)$ \\
\hline Other & $2(1.0)$ & $0(0.0)$ & $1(1.0)$ \\
\hline $\begin{array}{l}\text { Number of participants on analge- } \\
\text { sics in the past } 7 \text { days, No. (\%) }\end{array}$ & & $18(17.3)$ & $11(10.6)$ \\
\hline \multicolumn{4}{|l|}{ WOMAC, mean (SD) } \\
\hline Pain & $47.0(20.7)$ & $46.2(21.6)$ & $47.7(19.8)$ \\
\hline Stiffness & $47.0(25.6)$ & $45.8(25.6)$ & $48.2(25.6)$ \\
\hline Function & $45.9(21.0)$ & $45.8(21.4)$ & $45.9(20.6)$ \\
\hline Total & $46.2(20.4)$ & $45.9(21.0)$ & 46.5 (19.9) \\
\hline \multicolumn{4}{|l|}{ Physical function, mean (SD), s } \\
\hline Timed up and go & $11.3(3.7)$ & $11.1(4.1)$ & $11.4(3.3)$ \\
\hline 30-s chair stand & $8.8(3.7)$ & $9.0(3.9)$ & $8.7(3.5)$ \\
\hline 40-m fast-paced walk & $39.4(7.3)$ & $39.6(22.1)$ & $39.2(10.4)$ \\
\hline \multicolumn{4}{|l|}{ EuroQoL-5D, mean (SD), score } \\
\hline Index & $0.58(0.25)$ & $0.60(0.26)$ & $0.56(0.23)$ \\
\hline VAS & $67.3(15.5)$ & $66.9(17.1)$ & $67.8(13.7)$ \\
\hline \multicolumn{4}{|c|}{$\begin{array}{l}\mathrm{BMI}=\text { body mass index; } \mathrm{HEPA}=\text { health-enhancing physical activity; } \mathrm{IPAQ}=\text { International Physical Activity } \\
\text { Questionnaire; IQR = interquartile range; } \mathrm{MET}=\text { metabolic equivalent; } \mathrm{OA}=\text { osteoarthritis; } \mathrm{SD}=\text { standard } \\
\text { deviation; } \mathrm{VAS}=\text { visual analog scale; } \text { WOMAC = Western Ontario and McMaster University Osteoarthritis Index. }\end{array}$} \\
\hline
\end{tabular}


Table 2. Baseline Participant Knee Osteoarthritis Severity Scores

\begin{tabular}{|c|c|c|c|c|}
\hline Type of Score & $\begin{array}{l}\text { Total } \\
(n=326)\end{array}$ & $\begin{array}{c}\text { Intervention } \\
\text { Group } \\
(n=160)\end{array}$ & $\begin{array}{c}\text { Control } \\
\text { Group } \\
(n=166)\end{array}$ & $\begin{array}{c}P \\
\text { Value }^{a}\end{array}$ \\
\hline OA knee pain' intensity, mean (SD) & $63.1(17.4)$ & $62.6(17.5)$ & $63.6(17.4)$ & .636 \\
\hline Kellgren-Lawrence Grade, No. (\%) & & & & .861 \\
\hline 1 (Doubtful JSN, possible osteophytic lipping) & $78(24.3 \%)$ & $38(23.9 \%)$ & $40(24.7 \%)$ & \\
\hline $\begin{array}{l}2 \text { (Definite osteophytes, possible JSN on anteroposterior weight-bearing } \\
\text { radiograph) }\end{array}$ & $153(47.7 \%)$ & $80(50.3 \%)$ & $73(45.1 \%)$ & \\
\hline 3 (Multiple osteophytes, definite JSN, sclerosis, possible bony deformity) & $78(24.3 \%)$ & $36(22.6 \%)$ & $42(25.9 \%)$ & \\
\hline 4 (Large osteophytes, marked JSN, severe sclerosis and definitely bony) & $12(3.7 \%)$ & $5(3.1 \%)$ & $7(4.3 \%)$ & \\
\hline Patella position, mean (SD) & $0.90(0.24)$ & $0.91(0.24)$ & $0.90(0.24)$ & .751 \\
\hline Degree of pain-free active knee flexion, mean (SD) & $124.0(15.0)$ & $125.8(12.4)$ & $124.1(17.1)$ & .380 \\
\hline
\end{tabular}

Table 3. Results of Group Effect on WOMAC Pain Score Using Analysis of Covariance

\begin{tabular}{|c|c|c|c|c|c|c|c|c|}
\hline \multirow[b]{2}{*}{$\begin{array}{l}\text { Analysis } \\
\text { Performed }\end{array}$} & \multirow[b]{2}{*}{$\begin{array}{c}\text { Intervention } \\
\text { Group }(n=104), \\
\text { mean (SD) }\end{array}$} & \multirow[b]{2}{*}{$\begin{array}{l}\text { Control Group } \\
(n=104) \\
\text { mean (SD) }\end{array}$} & \multicolumn{3}{|c|}{ Model 1} & \multicolumn{3}{|c|}{ Model $2^{a}$} \\
\hline & & & $\begin{array}{l}\text { Between-Group } \\
\text { Difference } \\
(95 \% \mathrm{Cl})\end{array}$ & $\begin{array}{c}P \\
\text { Value }\end{array}$ & SE & $\begin{array}{l}\text { Between-Group } \\
\text { Difference } \\
(95 \% \mathrm{Cl})\end{array}$ & $\begin{array}{c}P \\
\text { Value }\end{array}$ & SE \\
\hline \multicolumn{9}{|l|}{ ITT analysis } \\
\hline Week 0 & $46.2(21.6)$ & $47.7(19.8)$ & & & & & & \\
\hline Week 24 & $28.8(23.4)$ & $44.3(22.3)$ & $\begin{array}{c}-15.5 \\
(-21.9 \text { to }-9.0)\end{array}$ & $<.001$ & 3.3 & $\begin{array}{c}-15.6 \\
(-20.5 \text { to }-10.7)\end{array}$ & $<.001$ & 2.5 \\
\hline \multicolumn{9}{|c|}{ Per-protocol analysis ${ }^{b}$} \\
\hline Week 0 & $47.6(21.3)$ & $47.6(19.7)$ & & & & & & \\
\hline Week 24 & $29.4(23.3)$ & $44.3(22.3)$ & $\begin{array}{c}-14.9 \\
(-21.4 \text { to }-8.4)\end{array}$ & $<.001$ & 3.3 & $\begin{array}{c}-16.0 \\
(-21.0 \text { to }-11.0)\end{array}$ & $<.001$ & 2.6 \\
\hline \multicolumn{9}{|c|}{ Imputed data analysis } \\
\hline Week 0 & $46.2(21.6)$ & $47.7(19.8)$ & & & & & & \\
\hline Week 24 & $28.9(24.1)$ & $44.6(22.8)$ & $\begin{array}{c}-15.8 \\
(-22.2 \text { to }-9.3)\end{array}$ & $<.001$ & 3.3 & $\begin{array}{c}-14.9 \\
(-20.1 \text { to }-9.8)\end{array}$ & $<.001$ & 2.6 \\
\hline \multicolumn{9}{|c|}{$\begin{array}{l}\text { Per-protocol analysis } \\
\text { with imputation }\end{array}$} \\
\hline Week 0 & $47.6(21.3)$ & $47.6(19.7)$ & & & & & & \\
\hline Week 24 & $29.5(23.3)$ & $44.8(22.4)$ & $\begin{array}{c}-15.3 \\
(-21.9 \text { to }-8.7)\end{array}$ & $<.001$ & 3.3 & $\begin{array}{c}-15.8 \\
(-20.9 \text { to }-10.7)\end{array}$ & $<.001$ & 2.6 \\
\hline
\end{tabular}

ment. ${ }^{46,47}$ Our study also suggests that if diagnosis of patients with patellofemoral joint osteoarthritis is followed by tailored interventions to improve knee biomechanics, this may reduce pain and disability. ${ }^{15}$

Unlike conventional mobilization therapy, that involves multiple treatment sessions at intense frequency, our technique can easily be performed in primary care practices. The approximate time needed for primary care physicians to learn PMT is about one hour, which includes an overview of the biomechanics of knee osteoarthritis and supervised practice on 3 to 4 patients. We observed a high patient compliance rate in our study, indicating that PMT is an acceptable treatment option for our patients.

Our study has some limitations. First, because of the lack of an active control arm, we are not certain if or how much the identified difference was attributable to the intervention. Second, our study duration was only 6 months, and the long-term efficacy of this intervention remains unclear. Third, the exclusion criteria and the single center study setting may also limit generalizability.

We conclude that PMT has the potential to reduce pain and improve function and quality of life for 
Table 4. Results of Group Effect on WOMAC Stiffness, Function, and Composite Scores, Physical Function Measures, and EuroQoL-5D Using ANCOVA

\begin{tabular}{|c|c|c|c|c|c|c|c|c|}
\hline \multirow[b]{2}{*}{ Type of Score } & \multirow[b]{2}{*}{$\begin{array}{c}\text { Intervention } \\
\text { Group }(n=104), \\
\text { mean (SD) }\end{array}$} & \multirow[b]{2}{*}{$\begin{array}{l}\text { Control Group } \\
(n=104), \\
\text { mean (SD) }\end{array}$} & \multicolumn{3}{|c|}{$\begin{array}{c}\text { Imputed Data Analysis } \\
\text { Model } 1\end{array}$} & \multicolumn{3}{|c|}{$\begin{array}{c}\text { Imputed Data Analysis } \\
\text { Model } 2^{\text {a }}\end{array}$} \\
\hline & & & $\begin{array}{l}\text { Between-Group } \\
\text { Difference } \\
(95 \% \mathrm{Cl})\end{array}$ & $\begin{array}{c}P \\
\text { Value }\end{array}$ & SE & $\begin{array}{l}\text { Between-Group } \\
\text { Difference } \\
(95 \% \mathrm{Cl})\end{array}$ & $\begin{array}{c}P \\
\text { Value }\end{array}$ & SE \\
\hline \multicolumn{9}{|l|}{ WOMAC (stiffness) } \\
\hline Week 0 & $45.7(25.6)$ & $48.2(25.6)$ & & & & & & \\
\hline Week 24 & $27.4(25.3)$ & $42.9(26.7)$ & $\begin{array}{c}-15.1 \\
(-22.7 \text { to }-7.5)\end{array}$ & $<.001$ & 3.8 & $\begin{array}{c}-13.9 \\
(-20.3 \text { to }-7.4)\end{array}$ & $<.001$ & 3.3 \\
\hline \multicolumn{9}{|l|}{ WOMAC (function) } \\
\hline Week 0 & $45.8(20.6)$ & $45.9(21.4)$ & & & & & & \\
\hline Week 24 & $27.7(23.9)$ & $43.0(22.5)$ & $\begin{array}{c}-15.2 \\
(-21.8 \text { to }-8.7)\end{array}$ & $<.001$ & 3.3 & $\begin{array}{c}-15.1 \\
(-20.2 \text { to }-9.9)\end{array}$ & $<.001$ & 2.6 \\
\hline \multicolumn{9}{|c|}{ WOMAC (composite) } \\
\hline Week 0 & $45.9(21.0)$ & $46.5(19.9)$ & & & & & & \\
\hline Week 24 & $27.9(23.2)$ & $43.3(21.8)$ & $\begin{array}{c}-15.1 \\
(-21.8 \text { to }-8.5)\end{array}$ & $<.001$ & 3.4 & $\begin{array}{c}-14.7 \\
(-20.2 \text { to }-9.3)\end{array}$ & $<.001$ & 2.7 \\
\hline \multicolumn{9}{|l|}{$\begin{array}{l}\text { 30-s chair stand, } \\
\text { repetitions }\end{array}$} \\
\hline Week 0 & $9.0(3.9)$ & $8.7(3.5)$ & & & & & & \\
\hline Week 24 & $10.3(3.8)$ & $8.5(2.9)$ & $\begin{array}{c}1.8 \\
(0.8 \text { to } 2.7)\end{array}$ & $<.001$ & 0.5 & $\begin{array}{c}1.5 \\
(0.8 \text { to } 2.2)\end{array}$ & $<.001$ & 0.3 \\
\hline \multicolumn{9}{|l|}{$\begin{array}{l}\text { 40-m fast-paced } \\
\text { walk, s }\end{array}$} \\
\hline Week 0 & $39.6(22.1)$ & $39.2(10.4)$ & & & & & & \\
\hline Week 24 & $34.6(9.4)$ & $38.4(10.7)$ & $\begin{array}{c}-3.4 \\
(-6.3 \text { to }-0.6)\end{array}$ & .019 & 1.5 & $\begin{array}{c}-3.4 \\
(-6.1 \text { to }-0.8)\end{array}$ & .012 & 1.3 \\
\hline \multicolumn{9}{|c|}{ Timed up and go, s } \\
\hline Week 0 & $11.1(4.1)$ & $11.4(3.3)$ & & & & & & \\
\hline Week 24 & $10.0(3.0)$ & $11.9(4.3)$ & $\begin{array}{c}-1.7 \\
(-2.8 \text { to }-0.7)\end{array}$ & .001 & 0.5 & $\begin{array}{c}-1.5 \\
(-2.4 \text { to }-0.7)\end{array}$ & $<.001$ & 0.4 \\
\hline \multicolumn{9}{|l|}{ EuroQol-5D index } \\
\hline Week 0 & $0.60(0.26)$ & $0.56(0.23)$ & & & & & & \\
\hline Week 24 & $0.72(0.25)$ & $0.60(0.23)$ & $\begin{array}{c}0.11 \\
(0.04 \text { to } 0.18)\end{array}$ & .001 & 0.03 & $\begin{array}{c}0.11 \\
(0.04 \text { to } 0.18)\end{array}$ & .001 & 0.03 \\
\hline \multicolumn{9}{|l|}{ EuroQoL-5D VAS } \\
\hline Week 0 & $66.9(17.1)$ & $67.8(13.7)$ & & & & & & \\
\hline Week 24 & $72.0(18.8)$ & $64.8(15.5)$ & $\begin{array}{l}6.7 \\
(1.6 \text { to } 11.8)\end{array}$ & .010 & 2.6 & $\begin{array}{c}7.2 \\
(2.7 \text { to } 11.8)\end{array}$ & .002 & 2.3 \\
\hline
\end{tabular}

\section{Table 5. Results of Group Effect on VAS Pain Score \& Pain-Free Active Knee Flexion of Individual Treated Knees Using Mixed Linear Regression}

\begin{tabular}{|c|c|c|c|c|c|c|c|c|}
\hline \multirow[b]{2}{*}{$\begin{array}{l}\text { Type of } \\
\text { Assessment }\end{array}$} & \multirow[b]{2}{*}{$\begin{array}{c}\text { Intervention } \\
\text { Group }(n=104) \text {, } \\
\text { mean (SD) }\end{array}$} & \multirow[b]{2}{*}{$\begin{array}{c}\text { Control Group } \\
(n=104) \\
\text { mean (SD) }\end{array}$} & \multicolumn{3}{|c|}{$\begin{array}{c}\text { Imputed Data Analysis } \\
\text { Model } 1\end{array}$} & \multicolumn{3}{|c|}{$\begin{array}{c}\text { Imputed Data Analysis } \\
\text { Model } 2^{\mathrm{a}}\end{array}$} \\
\hline & & & $\begin{array}{l}\text { Between-Group } \\
\text { Difference } \\
(95 \% \mathrm{Cl})\end{array}$ & $\begin{array}{c}P \\
\text { Value }\end{array}$ & SE & $\begin{array}{l}\text { Between-Group } \\
\text { Difference } \\
(95 \% \mathrm{Cl})\end{array}$ & $\begin{array}{c}P \\
\text { Value }\end{array}$ & SE \\
\hline \multicolumn{9}{|c|}{$\begin{array}{l}\text { Pain intensity total } \\
\text { (VAS) of treated knee }\end{array}$} \\
\hline Week 0 & $62.6(17.5)$ & $63.6(17.4)$ & & & & & & \\
\hline Week 24 & $42.1(24.2)$ & $57.7(23.0)$ & $\begin{array}{c}-15.6 \\
(-21.7 \text { to }-9.5)\end{array}$ & $<.001$ & 3.1 & $\begin{array}{c}-15.0 \\
(-20.5 \text { to }-9.5)\end{array}$ & $<.001$ & 2.8 \\
\hline \multicolumn{9}{|c|}{$\begin{array}{l}\text { Degree of pain-free } \\
\text { active knee flexion }\end{array}$} \\
\hline Week 0 & $125.8(12.4)$ & $124.1(17.1)$ & & & & & & \\
\hline Week 24 & $130.0(10.4)$ & $118.6(19.5)$ & $\begin{array}{c}11.0 \\
(6.7 \text { to } 15.3)\end{array}$ & $<.001$ & 2.2 & $\begin{array}{c}9.3 \\
(6.0 \text { to } 12.5)\end{array}$ & $<.001$ & 1.6 \\
\hline
\end{tabular}


patients with knee osteoarthritis. Future studies comparing PMT with other active controls will further confirm the benefits and facilitate the deployment of PMT in the real-world practice.

To read or post commentaries in response to this article, see it online at http://www.AnnFamMed.org/content/16/6/521.

Submitted May 17, 2018; submitted, revised, September 6, 2018; accepted September 20, 2018.

Trial Registration: Chinese Clinical Trial Registry ChiCTR-IPC-15006618

Key words: knee osteoarthritis; patellofemoral joint osteoarthritis; patella mobilization therapy; randomized clinical trial

Funding support: The study was funded by the Hong Kong College of Family Physician Research Fellowship Scheme 2014 (HKD 100,000). The funding body had no other role in the study.

Acknowledgments: The authors would like to thank Miss Lyan LY Chow and Miss Lucia WY Tam for helping with the administrative tasks, data collection and data entry. We also thank Dr Julian CY Fong, the radiologist from the Hong Kong College of Radiologists, for reporting the radiographs.

\section{References}

1. Felson DT. Clinical practice. Osteoarthritis of the knee. N Engl J Med. 2006;354(8):841-848.

2. Mamlin LA, Melfi CA, Parchman ML, et al. Management of osteoarthritis of the knee by primary care physicians. Arch Fam Med. 1998; 7(6):563-567.

3. Croft P, Porcheret M, Peat G. Managing osteoarthritis in primary care: the GP as public health physician and surgical gatekeeper. $\mathrm{Br}$ J Gen Pract. 2011;61(589):485-486.

4. Hutton I, Gamble G, McLean G, Butcher H, Gow P, Dalbeth N. Obstacles to action in arthritis: a community case-control study. Int J Rheum Dis. 2009;12(2):107-117.

5. Jamtvedt G, Dahm KT, Christie A, et al. Physical therapy interventions for patients with osteoarthritis of the knee: an overview of systematic reviews. Phys Ther. 2008;88(1):123-136.

6. Machado GC, Maher CG, Ferreira PH, et al. Efficacy and safety of paracetamol for spinal pain and osteoarthritis: systematic review and meta-analysis of randomised placebo controlled trials. BMJ. 2015;350:h1225.

7. da Costa BR, Reichenbach S, Keller N, et al. Effectiveness of nonsteroidal anti-inflammatory drugs for the treatment of pain in knee and hip osteoarthritis: a network meta-analysis. Lancet. 2017; 390(10090):e21-e33.

8. Barber JB, Gibson SJ. Treatment of chronic non-malignant pain in the elderly: safety considerations. Drug Saf. 2009;32(6):457-474.

9. Farrokhi S, Piva SR, Gil AB, Oddis CV, Brooks MM, Fitzgerald GK. Association of severity of coexisting patellofemoral disease with increased impairments and functional limitations in patients with knee osteoarthritis. Arthritis Care Res (Hoboken). 2013;65(4):544-551.

10. Hinman RS, Crossley KM. Patellofemoral joint osteoarthritis: an important subgroup of knee osteoarthritis. Rheumatology (Oxford). 2007:46(7):1057-1062.

11. Lankhorst NE, Damen J, Oei EH, et al. Incidence, prevalence, natural course and prognosis of patellofemoral osteoarthritis: the Cohort Hip and Cohort Knee study. Osteoarthritis Cartilage. 2017;25(5): 647-653.
12. McAlindon TE, Bannuru RR, Sullivan MC, et al. OARSI guidelines for the non-surgical management of knee osteoarthritis. Osteoarthritis Cartilage. 2014;22(3):363-388.

13. Fernandes L, Hagen KB, Bijlsma JW, et al.; European League Against Rheumatism (EULAR). EULAR recommendations for the non-pharmacological core management of hip and knee osteoarthritis. Ann Rheum Dis. 2013;72(7):1125-1135.

14. Hochberg MC, Altman RD, April KT, et al; American College of Rheumatology. American College of Rheumatology 2012 recommendations for the use of nonpharmacologic and pharmacologic therapies in osteoarthritis of the hand, hip, and knee. Arthritis Care Res (Hoboken). 2012;64(4):465-474.

15. Crossley KM, Stefanik JJ, Selfe J, et al. 2016 Patellofemoral pain consensus statement from the 4th International Patellofemoral Pain Research Retreat, Manchester. Part 1: Terminology, definitions, clinical examination, natural history, patellofemoral osteoarthritis and patientreported outcome measures. Br J Sports Med. 2016;50(14):839-843.

16. National Clinical Guideline Centre, National Institute for Health and Clinical Excellence: Guidance. Osteoarthritis: Care and Management in Adults. London, UK: National Institute for Health and Care Excellence (UK) Copyright National Clinical Guideline Centre; 2014.

17. Joshi S, Srivastava N, Kushwah S. Comparison between effectiveness of Maitland Compression Technique with medial glide and conventional therapy in patients with patellofemoral osteoarthritis. Indian J Physiother Occup Ther. 2014;8(3):220-226.

18. Crossley KM, Vicenzino B, Lentzos J, et al. Exercise, education, manual-therapy and taping compared to education for patellofemoral osteoarthritis: a blinded, randomised clinical trial. Osteoarthritis Cartilage. 2015;23(9):1457-1464.

19. Sit RWS, Chan KKW, Yip BHK, et al. Clinical effectiveness of patella mobilisation therapy versus a waiting list control for knee osteoarthritis: a protocol for a pragmatic randomised clinical trial. BMJ Open. 2018;8(3):e019103.

20. Altman R. Criteria for the classification of osteoarthritis of the knee and hip. Scand J Rheumatol. 1987;16(sup65):31-39.

21. Cook C, Mabry L, Reiman MP, Hegedus EJ. Best tests/clinical findings for screening and diagnosis of patellofemoral pain syndrome: a systematic review. Physiotherapy. 2012;98(2):93-100.

22. Szebenyi B, Hollander AP, Dieppe P, et al. Associations between pain, function, and radiographic features in osteoarthritis of the knee. Arthritis Rheum. 2006;54(1):230-235.

23. Kernan WN, Viscoli CM, Makuch RW, Brass LM, Horwitz RI. Stratified randomization for clinical trials. J Clin Epidemiol. 1999;52(1):19-26.

24. Schulz KF, Grimes DA. Allocation concealment in randomised trials: defending against deciphering. Lancet. 2002;359(9306):614-618.

25. Amis AA, Firer P, Mountney J, Senavongse W, Thomas NP. Anatomy and biomechanics of the medial patellofemoral ligament. Knee. 2003;10(3):215-220.

26. Feller JA, Amis AA, Andrish JT, Arendt EA, Erasmus PJ, Powers CM. Surgical biomechanics of the patellofemoral joint. Arthroscopy. 2007;23(5):542-553.

27. Mangus BC, Hoffman LA, Hoffman MA, Altenburger P. Basic principles of extremity joint mobilization using a Kaltenborn approach. J Sport Rehabil. 2002;11(4):235-250.

28. Berger MJ, Chess DG, Doherty TJ. Vastus medialis motor unit properties in knee osteoarthritis. BMC Musculoskelet Disord. 2011;12(1): 199.

29. McAlindon TE, Driban JB, Henrotin Y, et al. OARSI clinical trials recommendations: design, conduct, and reporting of clinical trials for knee osteoarthritis. Osteoarthritis Cartilage. 2015;23(5):747-760.

30. Bellamy N, Buchanan WW, Goldsmith CH, Campbell J, Stitt LW. Validation study of WOMAC: a health status instrument for measuring clinically important patient relevant outcomes to antirheumatic drug therapy in patients with osteoarthritis of the hip or knee. J Rheumatol. 1988;15(12):1833-1840. 
31. Dobson F, Hinman RS, Roos EM, et al. OARSI recommended performance-based tests to assess physical function in people diagnosed with hip or knee osteoarthritis. Osteoarthritis Cartilage. 2013; 21(8):1042-1052.

32. Fransen M, Edmonds J. Reliability and validity of the EuroQol in patients with osteoarthritis of the knee. Rheumatology (Oxford). 1999;38(9):807-813.

33. Gajdosik RL, Bohannon RW. Clinical measurement of range of motion. Review of goniometry emphasizing reliability and validity. Phys Ther. 1987;67(12):1867-1872.

34. Lee PH, Yu YY, McDowell I, Leung GM, Lam TH, Stewart SM. Performance of the international physical activity questionnaire (short form) in subgroups of the Hong Kong chinese population. Int J Behav Nutr Phys Act. 2011;8(1):81.

35. Kellgren JH, Lawrence JS. Radiological assessment of osteoarthrosis. Ann Rheum Dis. 1957;16(4):494-502.

36. Younger J, Gandhi V, Hubbard E, Mackey S. Development of the Stanford Expectations of Treatment Scale (SETS): a tool for measuring patient outcome expectancy in clinical trials. Clin Trials. 2012; 9(6):767-776.

37. Abbott JH, Robertson MC, Chapple C, et al; MOA Trial team. Manual therapy, exercise therapy, or both, in addition to usual care, for osteoarthritis of the hip or knee: a randomized controlled trial. 1: clinical effectiveness. Osteoarthritis Cartilage. 2013;21(4):525-534

38. van Buuren S. Multiple imputation of discrete and continuous data by fully conditional specification. Stat Methods Med Res. 2007;16(3): 219-242.

39. Rubin DB. Multiple Imputation for Nonresponse in Surveys. Hoboken, NJ: John Wiley \& Sons; 2004
40. Royston P, White IR. Multiple imputation by chained equations (MICE): implementation in Stata. J Stat Softw. 2011;45(4):1-20.

41. Angst F, Aeschlimann A, Stucki G. Smallest detectable and minimal clinically important differences of rehabilitation intervention with their implications for required sample sizes using WOMAC and SF-36 quality of life measurement instruments in patients with osteoarthritis of the lower extremities. Arthritis Rheum. 2001;45(4):384-391.

42. Sullivan PW, Lawrence WF, Ghushchyan V. A national catalog of preference-based scores for chronic conditions in the United States. Med Care. 2005;43(7):736-749.

43. Fransen M, McConnell s, Harmer AR, Van der Esch M, Simic M, Bennel KL. Exercise for osteoarthritis of the knee: a Cockrane systematic review. Br J Sports Med. 2015;49(24):1554-1557.

44. Smith TO, Davies L, Toms AP, Hing CB, Donell ST. The reliability and validity of radiological assessment for patellar instability. A systematic review and meta-analysis. Skeletal Radiol. 2011;40(4): 399-414.

45. Macri EM, Stefanik JJ, Khan KK, Crossley KM. Is tibiofemoral or patellofemoral alignment or trochlear morphology associated with patellofemoral osteoarthritis? A systematic review. Arthritis Care Res (Hoboken). 2016;68(10):1453-1470

46. Warden SJ, Hinman RS, Watson MA Jr, Avin KG, Bialocerkowski $A E$, Crossley KM. Patellar taping and bracing for the treatment of chronic knee pain: a systematic review and meta-analysis. Arthritis Rheum. 2008;59(1):73-83.

47. Callaghan MJ, Parkes MJ, Hutchinson CE, Gait AD, Forsythe LM, Marjanovic EJ, et al. A randomised trial of a brace for patellofemoral osteoarthritis targeting knee pain and bone marrow lesions. Ann Rheum Dis. 2015;74(6):1164-1170. 